\title{
Effect of Thermal Curing on Slurry Stability and Thermal Conductivity Coefficient of Aerated Concrete Based on Industrial Solid Wastes
}

\author{
Jun $\mathrm{Ji}^{1}$, Xiaosheng Liu ${ }^{2}$, Shengying Tan ${ }^{1}$, Meina Wang ${ }^{1}$, Wen $\mathrm{Ni}^{1}{ }^{*}$ \\ ${ }^{1}$ School of Civil and Resources Engineering, University of Science and Technology Beijing, Beijing 100083, PR China \\ ${ }^{2}$ Global Energy Interconnection Research Institute Co., LtD Chang-ping district, State Grid Corporation of China, \\ Beijing 102211, PR China
}

Corresponding Author Email: niwen@ces.ustb.edu.cn

https://doi.org/10.18280/ijht.370135

Received: 19 September 2018

Accepted: 27 December 2018

\section{Keywords:}

Aerated concrete, thermal conductivity coefficient (TCC), industrial solid wastes (ISWS), temperature slurry, flue gas desulfurization $(F G D)$ gypsum

\begin{abstract}
This paper explores the effect of curing temperature on the slurry stability and thermal conductivity coefficient (TCC) of aerated concrete based on industrial solid wastes, aiming to prepare a porous insulation material with such a concrete. Specifically, aerated concrete was prepared from the basic cementitious materials of steel slag (SS), blast furnace slag (BFS) and flue gas desulfurization (FGD) gypsum and the foaming agent of aluminum powder paste, and subjected to repeated tests and scanning electron microscopy. The results show that the slurry stability of the aerated concrete based on steel slag(SS)-blast furnace slag(BFS)-flue gas desulfurization (FGD)gypsum is jointed affected by fluid heat conduction and hydration rate of the cementitious material; the cementitious material with the specific surface area (SSA) of $350 \mathrm{~m}^{2} / \mathrm{kg}$ can achieve the best foaming effect under the curing temperature of $70{ }^{\circ} \mathrm{C}$, with a volume expansion rate of $305 \%$, while that with the SSA of $500 \mathrm{~m}^{2} / \mathrm{kg}$ can achieve the best foaming effect under $45^{\circ} \mathrm{C}$, with a volume expansion rate of $295 \%$; the latter material will undergo bubble collapse under the combined effects of temperature and pressure if cured under $70{ }^{\circ} \mathrm{C}$. Under the optimal foaming temperatures, the TCCs of the two groups of cementitious materials are respectively $0.086 \mathrm{~W} /(\mathrm{m} \cdot \mathrm{K})$ and $0.071 \mathrm{~W} /(\mathrm{m} \cdot \mathrm{K})$. In this case, both materials have good thermal insulation effect and can be used for exterior wall insulation.
\end{abstract}

\section{INTRODUCTION}

Aerated concrete is a lightweight porous material with low density, small thermal conductivity coefficient (TCC) and Class A combustion performance (noncombustible). It is generally produced by introducing air entraining agents like hydrogen peroxide, sodium bicarbonate or aluminum powder paste into a cementitious system. This material has been widely adopted for building insulation $[1,2]$. If taken as the external wall insulation material, aerated concrete can effectively reduce the overall TCC of the wall, leading to an over $35 \%$ decrease in building energy consumption. However, aerated concrete is mainly bound together by Portland cement, which consumes a huge amount of energy, produces many pollutants and emits lots of carbon dioxide in the production process [3]. The carbon dioxide emission is bound to exacerbate the greenhouse effect. To solve the problem, a possible solution lies in preparing aerated concrete from industrial solid wastes (ISWs) with similar compositions as cement, such as steel slag (SS), blast furnace slag (BFS) and fly ash. In addition to reducing energy consumption, this solution can consume a huge volume of tailings and control ISWs pollution, laying the basis for energy conservation, emission reduction and sustainable development of resources $[4,5]$.

During the foaming process, the stability of the slurry has a great influence on the mechanical properties and TCC of the material. The slurry should be kept stability to produce a uniform microporous structure. To this end, the ordinary
Portland cement is often subjected to autoclaving at $105{ }^{\circ} \mathrm{C}$ and $1.5 \mathrm{MPa}[6]$. Unlike the ordinary Portland cement, the cementitious material made of steel slag (SS), blast furnace slag (BFS) and flue gas desulfurization (FGD) gypsum gains strength mainly through the generation of ettringite rather than tobermorite $[7,8]$. However, the ettringite will lose stability at above $80{ }^{\circ} \mathrm{C}$ [9]. This means autoclaving does not apply to the preparation of aerated concrete based on steel slag (SS), blast furnace slag (BFS) and FGD gypsum.

Some studies have found that the TCC of aerated concrete can reach $0.093 \mathrm{~W} /(\mathrm{m} \cdot \mathrm{k})$, if the autoclaved cement is replaced with steel slag (SS) and blast furnace slag (BFS). This is because the low aluminum content of the cementitious system suppresses the formation of ettringite in the early phase, and the later phase hydration product of the system is mainly tobermorite $[10,11]$. Besides, many scholars have proved that increasing the curing temperature can effectively improve the early strength and shorten the initial setting time of concrete. During the preparation of aerated concrete, the stability of the slurry is affected by the heat conduction between three phases (gas, liquid and solid) as well as the hydration rate of the cementitious material. However, the slurry stability under these two factors has not been widely explored.

Currently, many scholars are verifying whether it is feasible to replace the autoclaving process in foam concrete preparation with increasing curing temperature. The cementitious material is gradually changing from cement to fly ash, shale powder and steel slag (SS), while the traditional air entraining agent of aluminum powder is being substituted with 
potassium permanganate and zinc powders, which boast higher calorific values. The substitution aims to speed up the fluid heat transfer and minimize the initial setting time [12-14]. For example, Xia et al. prepares aerated concrete without autoclaving from fly ash (63.5 \% 65.5\%), cement (20\% 22\%) and lime (10\%), and applies the preparation system to experiments; the results show that the initial reaction temperature was $31 \sim 34{ }^{\circ} \mathrm{C}$, the foaming rate agreed with the hydration rate, and the slurry had excellent stability [15]. Wang and Lin prepares aerated concrete with 60 65\% shale fragments and 20 30\% cement, and cures the concrete at $60 \sim 80{ }^{\circ} \mathrm{C}$, revealing that the product satisfies the Test Methods of Autoclaved Aerated Concrete (GB/T 11969-2008) [16]. Xu et al. observes that the initial setting time of aerated concrete shortened from $110 \mathrm{~min}$ at $20^{\circ} \mathrm{C}$ to $50 \mathrm{~min}$ at $60^{\circ} \mathrm{C}$, indicating the suppressing effect of thermal curing on the initial setting time [17].

The initial setting of slurry is a fluid thickening process, in which the heat conduction is a combination of convective heat transfer and solid heat transfer. Hence, the initial setting temperature of the foam slurry cannot be characterized by the curing temperature, but the internal temperature of the slurry. In view of this, Pan et al. and Fan et al. add surfactants to enhance foam slurry stability $[18,19]$. Wee and Daneti places 10 kinds of typical surfactants under different temperatures, and observes the effect of temperature on the foaming performance, revealing that the optimal foaming temperature falls within $20 \sim 30{ }^{\circ} \mathrm{C}$ and the anionic foaming agent is more stable than other agents [20]. Zhang et al. empirically set the water-cement ratio to 0.50 , prepared aerated concrete through chemical foaming, and characterized the concrete stability with the measured foaming volume of the slurry [21].

In the above studies, the concrete is still partly made of cement. There is no report on the preparation of aerated concrete from steel slag (SS), blast furnace slag (BFS) and FGD gypsum, without any addition of cement. To make up for this gap, this paper prepares aerated concrete from the basic cementitious materials of steel slag (SS), blast furnace slag (BFS) and FGD gypsum and the foaming agent of aluminum powder paste, and examines the effect of thermal curing on the slurry stability and TCC of the aerated concrete. To assess the feasibility of replacing cement with ISWs like steel slag (SS) and blast furnace slag (BFS), the three cementitious materials, namely, steel slag (SS), blast furnace slag (BFS) and FGD gypsum, were all ground to the specific surface area (SSA) of $350 \mathrm{~m}^{2} / \mathrm{kg}$ and $500 \mathrm{~m}^{2} / \mathrm{kg}$, in reference to the SSA of ordinary Portland cement $\left(350 \mathrm{~m}^{2} / \mathrm{kg}\right)$. Considering the small early strength of ISWs-based cementitious materials, the watercement ratio was controlled at the small value of 0.45 , as that in the aerated concrete made from cement generally lies between 0.45 and 0.6 .

\section{METHODOLOGY}

\subsection{Raw materials}

Our experiment uses the steel slag (SS) produced by Yuhua Iron and Steel Co., Ltd., the water granulated blast furnace slag (BFS) produced by Xintai Iron \& Steel Corp., Ltd., the FGD gypsum produced by Beijing Gypsum Line Plant, and the water-soluble aluminum powder paste produced by BBMG Corporation.

\subsection{Test conditions}

The steel slag (SS), blast furnace slag (BFS) and FGD gypsum were divided into two groups. The materials in Group A350 are $350 \mathrm{~m}^{2} / \mathrm{kg}$ in the SSA, and those in Group A500 are $500 \mathrm{~m}^{2} / \mathrm{kg}$ in the SSA. The three materials were mixed by the ratio in Table 1 below at a high rate for $30 \mathrm{~s}$ in a mixer. Then, the mixture was added $40{ }^{\circ} \mathrm{C}$ and mixed for another $60 \mathrm{~s}$. After that, the aluminum powder paste was added and the mixture was mixed for another $15 \mathrm{~s}$ at a high rate. The resulting slurry was quickly poured into several molds, and cured at $20{ }^{\circ} \mathrm{C}$, $45^{\circ} \mathrm{C}$ and $70{ }^{\circ} \mathrm{C}$, respectively. Each mold was installed with a thermocouple at the center. The slurry temperature was measured by a four-channel thermometer. The volume change of the slurry was recorded by a caliper and used to compute the volume expansion ratio.

Table 1. Material composition and curing temperatures of the cementitious materials

\begin{tabular}{ccccccc}
\hline Number & $\begin{array}{c}\text { SS } \\
(\mathbf{w} \%)\end{array}$ & $\begin{array}{c}\text { BFS } \\
(\mathbf{w} \%)\end{array}$ & $\begin{array}{c}\text { FGD } \\
(\mathbf{w} \%)\end{array}$ & $\begin{array}{c}\text { Aluminum Paste } \\
(\mathbf{w} \%)\end{array}$ & $\begin{array}{c}\text { Curing Temperature } \\
\left({ }^{\circ} \mathbf{C}\right)\end{array}$ & $\begin{array}{c}\text { Specific Volumetric Dilatation } \\
(\boldsymbol{\%})\end{array}$ \\
\hline A500 & 38 & 60 & 12 & 0.3 & 20 & 198 \\
A500 & 38 & 60 & 12 & 0.3 & 45 & 295 \\
A500 & 38 & 60 & 12 & 0.3 & 70 & 277 \\
A350 & 38 & 60 & 12 & 0.3 & 20 & 153 \\
A350 & 28 & 60 & 12 & 0.3 & 45 & 252 \\
A350 & 28 & 60 & 12 & 0.3 & 70 & 305 \\
\hline
\end{tabular}

\section{TEST RESULTS AND DISCUSSION}

\subsection{Effect of curing temperature on slurry stability of aerated concrete}

Figure 1 describes the variation in volume expansion rate of the samples with curing temperatures. Obviously, the volume expansion ratio of the two cementitious materials both soared under high curing temperatures. For the A350 cementitious material, the volume expansion ratio was $64.71 \%$ and $99.35 \%$, respectively, under $45{ }^{\circ} \mathrm{C}$ and $70{ }^{\circ} \mathrm{C}$; for A500 cementitious material, the volume expansion ratio stood at $48.99 \%$ and $39.90 \%$, respectively, under the two temperatures. The rapid growth of the volume expansion ratio can be explained as follows.

Both cementitious materials release a large amount of $\mathrm{OH}-$ in water, creating an alkaline environment. Under this condition, the aluminum powder paste produces gas through chemical reaction. The numerous gas bubbles are independent and uniformly distributed. When the bubbles are just formed, the slurry is in the liquid state and undergoes convective heat transfer as its temperature differs from the ambient temperature. Once heated, the bubbles become increasingly 
unstable. The gas source starts to expand rapidly when the gas pressure surpasses the ultimate shear stress of the slurry (the sum of the viscous resistance and the hydrostatic pressure) [22, 23].

The temperature has an impact on the heat conduction of the fluid. With the increase in temperature, the Brownian motion of the fluid intensifies, and the viscosity of the liquid film first rises and then decreases. The continued growth in temperature will reduce the thickness of the bubble film. As water condenses on the cementitious material, the dead-weight of the material gradually increases. When the dead-weight exceeded the sum of the pressure in the pores and the viscous force on the surface of the bubbles, the pores will be crushed, the bubbles will collapse [24], and the bubbles will cease to exist. That is why A500 had a smaller volume expansion rate than A350 under $70^{\circ} \mathrm{C}$.

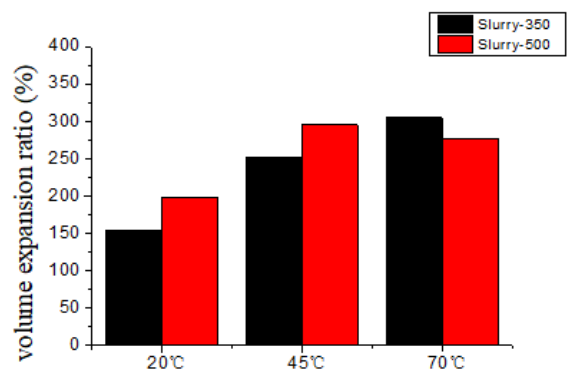

Figure 1. Variation in volume expansion rate with curing temperatures

To further disclose the effect of temperature on slurry stability, the slurry temperature was measured by the thermocouple in each mold and the time-variation in that temperature is presented in Figure 2. It can be seen that the slurry temperature of A350 first declined and then increased under the curing temperature of $20^{\circ} \mathrm{C}$. This is because the A350 cementitious material has a small SSA and a low solubility in the initial phase. At the beginning, the steel slag (SS) and blast furnace slag (BFS) are hydrated at a slow rate, and only a few minerals join the hydration. Thus, the solution is low in the contents of $\mathrm{OH}-$ and $\mathrm{Ca} 2+$. Compared with $\mathrm{A} 500$, the $\mathrm{A} 350$ cementitious material remains in the fluid state for a long time. Meanwhile, the slurry of A350 will cool down as its heat flows toward the relatively cool environment. As the hydration continues, more and more heat is released, pushing up the slurry temperature.

It can also be seen in Figure 2 that A500 was hydrated faster than A350 in the first 20min. Hydration is an exothermic reaction process. A large amount of heat is released in the initial phase due to the concentrated generation of ettringites. Numerous micron-sized particles wrap up the foams and get involved in the hydration on the foam walls. Comparatively, the slurry with a short initial setting time can restrain and fix the bubbles, and keep the pores stable. In the foaming process, more gas is retained in such a slurry despite the hydration reaction $[25,26]$.

The hydration rate of $\mathrm{A} 350$ is relatively slow. The aluminum powder paste has released a huge amount of hydrogen before the bubbles are covered by the hydrated solid layer. The gas holding property of the slurry is so poor that the bubbles float upwards. The molecules in small bubbles with high internal pressure migrate cross the liquid film towards the adjacent big bubbles with low internal pressure. As a result, the small bubbles merge into large bubbles and escape the solution (Figure 3). Due to the slow hydration rate, the A350 slurry is hotter than A500 slurry in the later phase. Therefore, it is concluded that the bubble bursts at low temperatures are mainly the result of gas diffusion and bubble combination.

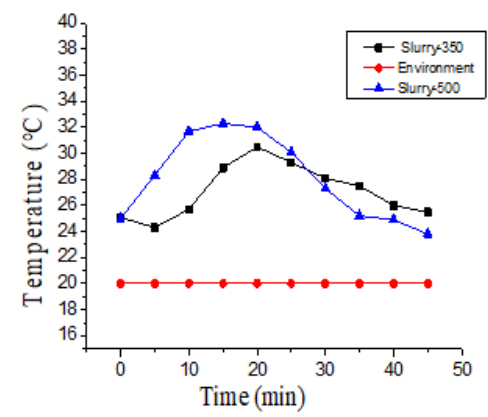

Figure 2. Variation in volume expansion rate with curing temperatures

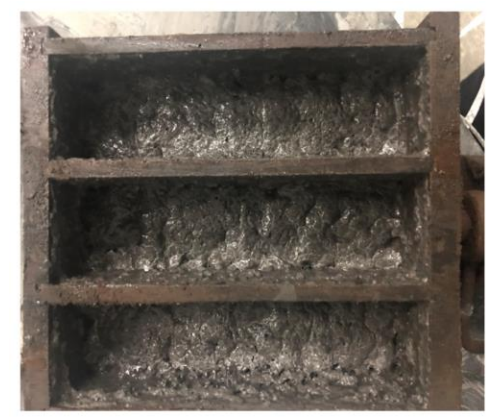

Figure 3. Escape of bubbles under $20{ }^{\circ} \mathrm{C}$

Under the curing temperature of $45^{\circ} \mathrm{C}$ (Figure 4), A350 and A500 both hydrated while foaming, and both had good gas holding effects. The volume expansion rate of the two slurries was respectively $252 \%$ and $295 \%$, much higher than those under $20^{\circ} \mathrm{C}$. Under this curing temperature, the first $15 \mathrm{mins}$ is the induction period of hydration of the cementitious material [27]. The A500 is hydrated faster than A350. The hydration releases a lot of heat, which is transferred to the slurry. Meanwhile, bubbles are generated in the initial 15mins. As the fluid temperature increases in a short time, the bubbling rate of the slurry starts to pick up speed. After all, the solution can dissolve the reactants and the reaction products more rapidly under high temperatures. The strong dissolution ability benefits the hydration reaction, leading to an increase in the gas production per unit time and the amount of gas in the slurry.

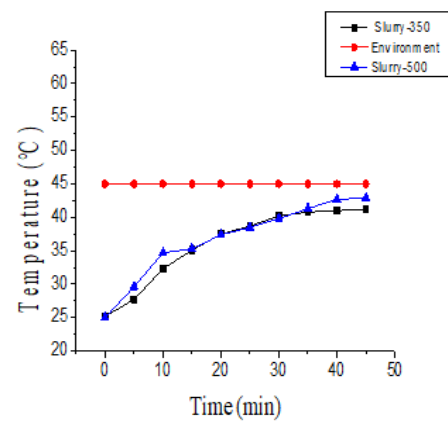

Figure 4. Variation in slurry temperature under $45{ }^{\circ} \mathrm{C}$

Figure 5 displays the time variation in slurry temperature under $70^{\circ} \mathrm{C}$. As shown in Figure 4, the slurry stability is mainly 
under the combined effect of bubble thermal stability and the hydration rate. The A500 is hydrated faster than the A350. In the early phase, the slurry of A500 quickly turns from the fluid state to the plastic state, and the fluid heat conduction becomes solid heat conduction. The bubble collapses under the deadweight of the slurry and the thinning of bubble walls (Figure 6). The collapse creates lots of voids on the slurry surface, expanding the heat convection area. In the later phase, the A500 slurry continuous to grow. As the temperature rises, the Marangoni effect is weakened by the fluid heat conduction and gas expansion, and the liquid film is less viscous and less strong, resulting in a decrease in bubble stability. At the same time, the plasticizing of the slurry is accelerated, and the bubbles merge and rupture more rapidly under the deadweight. Hence, it can be considered that the bubble collapse under high temperatures is the combined result of temperature and pressure.

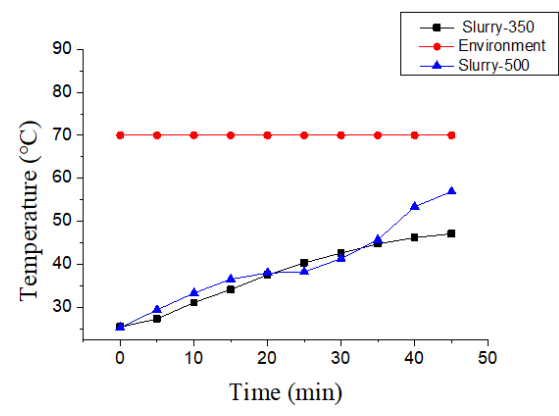

Figure 5. Variation in slurry temperature under $70^{\circ} \mathrm{C}$

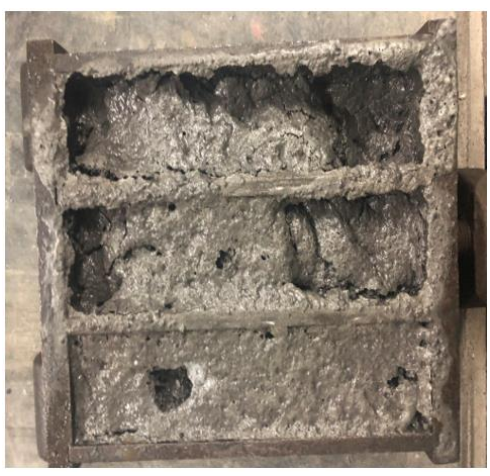

Figure 6. Bubble collapse

\subsection{Effect of curing temperature on aerated concrete TCC}

After three days of curing, the samples were subjected to TCC measurement by the flat band method and porosity measurement by the mercury intrusion method. The measured results are shown in Table 2 and Figure 7. It can be seen that the TCC of the aerated concrete decreased with the growth in curing temperature (except for bubble collapse). The reason lies in the fact that thermal curing transforms the unstable gasliquid-solid three-phase slurry into the stable gas-solid twophase system, turning the bubbles into pores. When the pore diameter is less than $4 \mathrm{~mm}$, the overall heat transfer performance is basically not affected by convective heat transfer or radiant heat transfer. Since the TCC of the air $(0.026 \mathrm{~W} /(\mathrm{m} \cdot \mathrm{k}))$ is way smaller than that of ordinary concrete $(1.4 \mathrm{~W} /(\mathrm{m} \cdot \mathrm{k}))$, most of the heat of aerated concrete is transferred by solid heat conduction after the formation of pores. There are two paths for heat to transfer in the voids: a quarter of a circumference and less than a quarter of a circumference (Figure 8). The solid TCC depends on the porosity of the material. The higher the porosity, the longer the heat transfer path, and the more the energy loss. To sum up, thermal curing facilitates the formation of a porous structure and reduces the TCC of the cementitious material.

Table 2. Porosities and TCCs of foam concrete under different curing temperatures

\begin{tabular}{cccc}
\hline Number & $\begin{array}{c}\text { Curing } \\
\text { Temperature }\left({ }^{\circ} \mathrm{C}\right)\end{array}$ & $\begin{array}{c}\text { Porosity } \\
(\mathbf{\%})\end{array}$ & $\begin{array}{c}\text { TCC } \\
(\mathbf{W} / \mathbf{m} \cdot \mathbf{K})\end{array}$ \\
\hline A350 & 20 & 48.65 & 0.157 \\
A350 & 45 & 66.27 & 0.094 \\
A350 & 70 & 73.18 & 0.086 \\
A500 & 20 & 59.71 & 0.131 \\
A500 & 45 & 78.65 & 0.071 \\
A500 & 70 & 83.5 & 0.117 \\
\hline
\end{tabular}

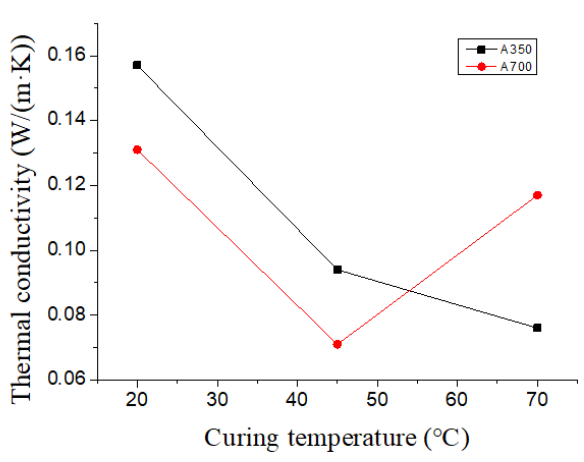

Figure 7. Normal temperature TCC variation with curing temperatures
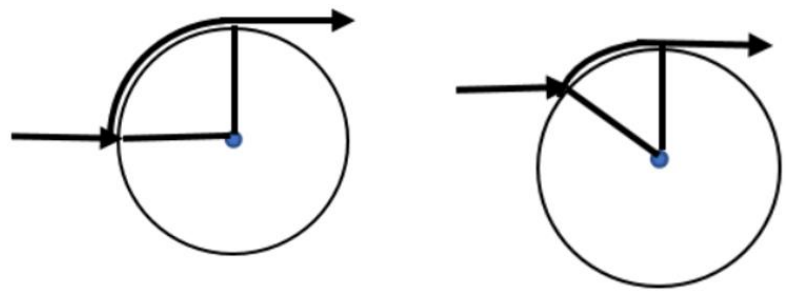

Figure 8. Heat transfer paths in solid

The above analysis shows that thermal curing affects the material porosity, and thus the TCC of the material. According to the Maxwell model $[28,29]$, the TCC is linearly correlated with porosity:

$\lambda=\frac{2 \lambda 1+\lambda 2+2 \mathrm{~V}(\lambda 2-\lambda 1) \lambda 1}{2 \lambda 1+\lambda 2-\mathrm{V}(\lambda 2-\lambda 1)}$

where $\lambda 1$ is the TCC of the continuous phase; $\lambda 2$ is the TCC of the dispersed phase; $\lambda$ is the TCC of the material; $\mathrm{V}$ is the porosity. The meanings of these parameters are the same in the subsequent analysis.

The linear relationship between TCC and porosity was measured in our test. The results (Figure 9) show that the TCC is correlated with porosity for the aerated concrete made from steel slag (SS), blast furnace slag (BFS) and FGD gypsum, but the coefficient of determination $\mathrm{R} 2=0.954$. The reason is that the Maxwell model characterizes the thermal conductivity of the material formed by uniform and independent spheres that are irregularly dispersed in the matrix, while the TCC of the 
aerated concrete, unlike that of other two-phase composites, not only hinges on the TCCs of its solid and gas phases, but also the relative content, morphology, distribution and interaction of the pores (which are formed from the bubbles). Of course, porosity is the dominant impactor of the TCC of the aerated concrete [30, 31]. For aerated concrete, the inter-pore distance shortens with the growth in porosity. In this case, the walls of the pores will contact each other, and the pores may even get connected. The interaction between the pores creates a thermal conduction chain along the heat flow.

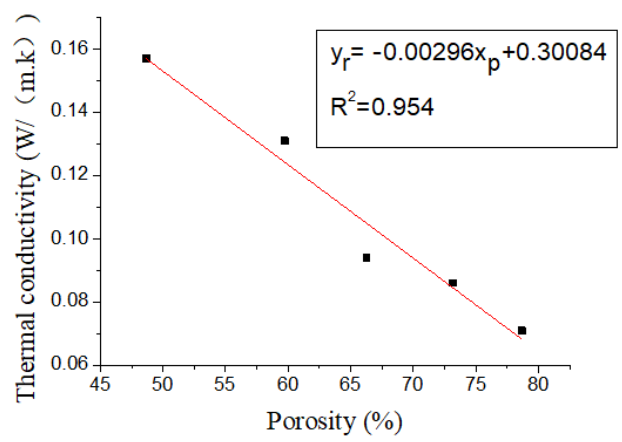

Figure 9. Relationship curve between TCC and porosity

Whereas the Maxwell model neglects the effect of bubble shape on the TCC, Hasselman et al. improved the Maxwell model considering how the size of dispersed spheres $(n=3)$ affects the thermal conductivity of the material. The resulting Hasselman model [32] can be expressed as:

$\lambda=\lambda 1 \frac{[\lambda 2(1+2 \alpha)+2 \lambda 1]+2 \mathrm{~V}[\lambda 2(1-\alpha)-\lambda 1]}{[\lambda 2(1+2 \alpha)+2 \lambda 1]-2 \mathrm{~V}[\lambda 2(1-\alpha)-\lambda 1]}$

where, $\alpha$ is the size coefficient of the spherical dispersed phase. This coefficient is negatively correlated with the sphere size. According to the Hasselman model, the TCC of aerated concrete is affected by the porosity and pore shape, while the curing temperature restricts the formation and distribution of pores.

Next, the scanning electron microscopy was performed on the samples with the same magnification at different temperatures. The results (Figure 10) show that the temperature growth caused the expansion of pore diameter, thinning of pore walls and uniformization of pore diameter in the aerated concrete.

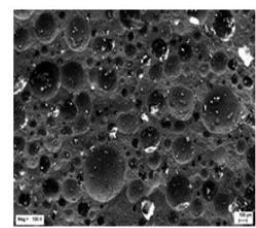

$20^{\circ} \mathrm{C}$

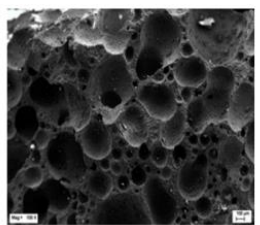

$45^{\circ} \mathrm{C}$

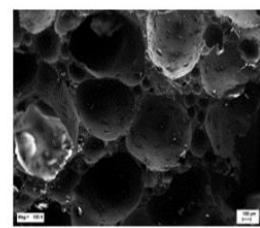

$70^{\circ} \mathrm{C}$
Figure 10. SEM images on microstructures of aerated concretes at different temperatures

\subsection{Mechanism analysis of ISWs-based aerated concrete}

The above results show that the concrete made from steel slag (SS), blast furnace slag (BFS) and FGD gypsum has a higher foaming temperature than ordinary Portland concrete, which may be attributable to the hydration products of its cementitious material. According to the SEM results on A350 aerated concrete (Figure 11), a small amount of ettringites and $\mathrm{C}$-S-H gel were formed under the curing temperature of $20^{\circ} \mathrm{C}$, but the products had not crystallized, leaving a few bulges on the SEM image; almost no hydration products had special morphology. Under the curing temperature of $45^{\circ} \mathrm{C}$, the needle-like ettringite outcrops were very obvious, the gaps were covered with small ettringites, and the gel formed clusters and became entangled with ettringites. Under the curing temperature of $70^{\circ} \mathrm{C}$, ettringite crystals grew thicker and thicker. With the increase of the ambient temperature, the silicon (aluminum)-oxygen tetrahedron dissociated at a faster speed from the blast furnace slag (BFS) in the system. In the meantime, the steel slag (SS) is hydrated more rapidly, making the solution more alkalinized. This leads to the generation of a huge amount of ettringites. Therefore, a lot of agglomerated gel can be observed on the pores and the particle surface. This means ordinary Portland cement has a different hydration mechanism from that of the cementitious material based on steel slag (SS), blast furnace slag (BFS) and FGD gypsum. The ordinary Portland cement can be hydrated rapidly, producing a large amount of tricalcium silicate, dicalcium silicate and aluminum aluminate in the early phase, and the aerated concrete made from the cement has a good gas retention effect under normal temperature. By contrast, the cementitious material based on steel slag (SS), blast furnace slag (BFS) and FGD gypsum hydrates slowly under the normal temperature, which suppresses the gas retention of aerated concrete, making it hard to foam; the main hydration products of the material include ettringite and C-S-H gel.

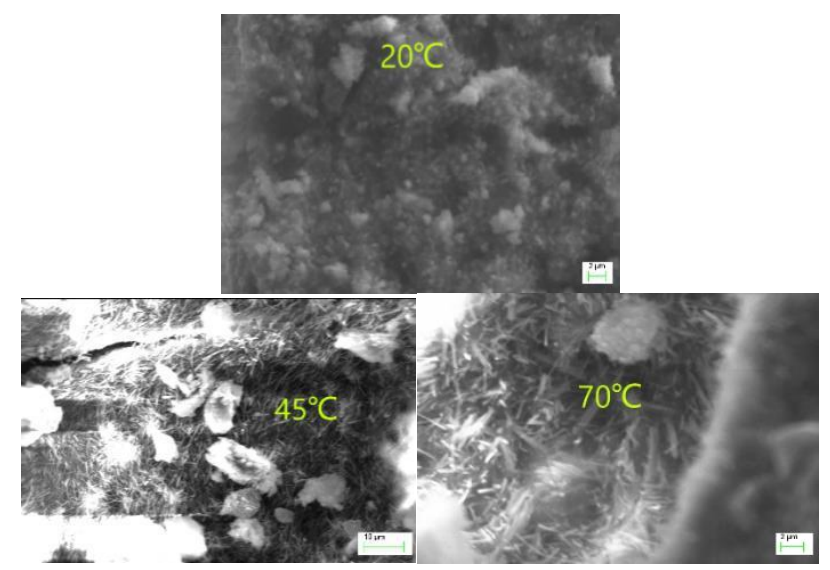

Figure 11. SEM results on A350 under different curing temperatures

\section{CONCLUSIONS}

a) The slurry stability of the aerated concrete based on steel slag (SS)-blast furnace slag (BFS)-FGD gypsum is affected jointly by fluid heat conduction and hydration rate. When the temperature is too low, the hydration rate lags behind the poreforming rate, resulting in the escape of bubbles; When the temperature is too high, the cementitious material condenses too early, and the bubbles burst and collapse under the action of temperature and slurry pressure.

b) The hydration rate of the cementitious material hinges both on the temperature and the material SSA. The optimal curing temperature can be selected according to the SSA of the cementitious material. Under the curing temperature of $70^{\circ} \mathrm{C}$, the aerated concrete based on steel slag (SS)-blast furnace slag 
(BFS) can achieve high slurry stability and good foaming effect, when it has a similar SSA with cement.

c) The cementitious material based on steel slag (SS)-blast furnace slag (BFS)-FGD gypsum has a poorer gas retention effect than ordinary Portland cement under the same temperature, because its hydration products (ettringite and CS-H gel) are hydrated slower than the early hydration product (tricalcium silicate) of the cement.

d) The TCC of the aerated concrete based on steel slag (SS)blast furnace slag (BFS)-FGD gypsum is severely affected by the thermal curing environment, and the effect is related to the porosity, pore diameter and pore shape.

\section{ACKNOWLEDGMENT}

The authors would like to thank fund project: Research and Application of Key Technologies for Major Fire-Fighting Equipment of Large Converter Transformer in Extra-High Voltage Converter Stations, a special key program of the State Grid (5455DW180023).

\section{REFERENCES}

[1] Masi G, Rickard WDA, Vickers L. (2014). A comparison between different foaming methods for the synthesis of light weight geopolymers. Ceramics International 40(9): 13891-13902.

https://doi.org/10.1016/j.ceramint.2014.05.108

[2] Liu Y, Bo SL, Hu ZT. (2017). Autoclaved aerated concrete incorporating waste aluminum dust as foaming agent. Construction and Building Materials 148: 140-147. https://doi.org/10.1016/j.conbuildmat.2017.05.047

[3] Miller SA, Horvath A, Monteiro PJM. (2016). Readily implementable techniques can cut annual $\mathrm{CO}_{2}$ emissions from the production of concrete by over $20 \%$. Environ. Res. Lett 11: 074029.

[4] Matsui K, Kikuma J, Tsunashima M, Ishikawa T, Matsuno SY, Ogawa A, Sato M. (2011). In situ timeresolved X-ray diffraction of tobermorite formation in autoclaved aerated concrete: Influence of silica source reactivity and Aladdition. Cem. Concr. Res 41(5): 510519. https://doi.org/10.1016/j.cemconres.2011.01.022(78)

[5] Chen YL, Chang JE, Lai YC, Melissa Chou MI. (2017). A comprehensive study on the production of autoclaved aerated concrete: effects of silicalime-cement composition and autoclaving conditions. Construction and Building Materials 153: 622-629. https://doi.org/10.1016/j.conbuildmat.2017.07.116

[6] Wu Z. (2002). The development and application of building materials with fly ash. Beijing: Chinese Buiding Materials Industry Press.

[7] Cui XW, Ni W, Ren C. (2017). Hydration mechanism of all solid waste cementitious materials based on steel slag and blast furnace slag. Chinese Journal of Materials Research 31(9): 688-571. https://doi.org/10.11901/1005.3093.2016.741

[8] Wang Q, Yan PY. (2008). Early hydration characteristics and paste structure of complex binding material containing high- volume steel slag. Journal of the Chinese Ceramic Society 36(10): 1406-1411. https://doi.org/10.14062/j.issn.0454-5648.2008.10.027
[9] Yan P, Qin X, Yang W, Peng J. (2001). The semiquantitative determination and morphplogy of ettringite in pastes containing expansive agent cured in elevated temperature. Cement and Concrete Research (31): 1285-1290. https://doi.org/10.1016/S00088846(01)00563-4

[10] Baspinar MS, Demir I, Kahrama E, Gorhan G. (2014). Utilization potential of fly ash together with silica fume in autoclaved aerated concrete production. KSCE J. Civil. Eng. 18: 47-52.

[11] Yuan B, Straub C, Segers S, Yu QL, Brouwers HJH. (2017). Sodium carbonate activated slag as cement replacement in autoclaved aerated concrete. Ceramics International 43: 6039-6047. https://doi.org/10.1016/j.ceramint.2017.01.144

[12] Sanjayan JG, Nazari A, Chen L. (2015). Physical and mechanical properties of lightweight aerated geopolymer. Construction and Building Materials 79: 236-244. https://doi.org/10.1016/j.conbuildmat.2015.01.043

[13] Narayanan N, Ramamurthy K. (2000). Microstructural investigations on aerated concrete. Cement and Concrete Research 30(3): 457-464. https://doi.org/10.1016/S00088846(00)00199-X

[14] Maini BB. (1985). Laboratory evaluation of foaming agents for high temperature applications-II, measurements of thermal stability and foam mobility in porous media. Petroleum society of CIM, 85-36-30, 347360.

[15] Xia YQ, Yan Y, Hu ZH. (2013). Utilization of circulating fluidized bed fly ash in preparing non-autoclaved aerated concrete production. Construction and Building Materials 47: 1461-1467. https://doi.org/10.1016/j.conbuildmat.2013.06.033

[16] Wang CQ, Lin XY. (2018). Utilization of oil-based drilling cuttings pyrolysis residues of shale gas for the preparation of non-autoclaved aerated concrete. Construction and Building Materials 162: 359-368. https://doi.org/10.1016/j.conbuildmat.2017.11.151

[17] Xu W, Qian GL, Hua ZL. (2011). Experimental study on the preparation of foam concrete by chemical method. Concrete and Cement Products (12): 1-4.

[18] Pan ZH, Cheng L, Li DX. (2002). Research on the preparation technology of new high-performance foam concrete. New Building Materials (5): 1-5.

[19] Fan LL, Yang Y, Zhu BR. (2012). Experimental study on the setting time of foam concrete. New Building Materials (7): 46-48.

[20] Wee TH, Daneti SB. (2011). Effect of W/C ratio on airvoid system of foamed concrete and their influence on mechanical properties. Mag. Concr. Res 63(8): 583-595.

[21] Zhang YF, Chen YM, Guo ZG, Xie HD. (2013). Study on the stability of foamed concrete by chemical foaming. Concrete 5 .

[22] Dong JH, Li ZY. (2010). Temperature effect on the exothermic behavior of cement hydration. Journal of Building Materials 10(13): 676-679: https://doi.org/1007-9629(2010) 05-0675-03

[23] Liu DS, Chen XY. (2006). Effect of temperature on foam stability. China Off Shore Platform 12(4): 19-22.

[24] Ma PS. (2008). Chemical Data Course. Tianjin: Tianjin University Press.

[25] Tang M, Xu LX. (2013). Foam concrete material and engineering application. Beijing: China Construction Industry Press, 135-138. 
[26] Schober G. (1992). Effect of size distribution of air porosity in AAC on compressive strength. in: A.A. Wittmann (Ed.), Advances in Autoclaved Aerated Concrete, Balkema, Rotterdam, 77-81.

[27] Amran YHM, Farzadnia N, Ali AAA. (2015). Properties and applications of foamed concrete, a review. Construction and Building Materials 101: 990-1005

[28] Kingery WD. (1959). J Am Ceram Soc 42: 617

[29] Godbee HW. (1966) J Appl Phys 37: 56
[30] Ducman V, Korat L. (2016). Characterization of geopolymer fly-ash based foams obtained with the addition of $\mathrm{Al}$ powder or $\mathrm{H}_{2} \mathrm{O}_{2}$ as foaming agents. Materials Characterization 113: 207-213.

[31] Zhu M, Wang FG. (2013). Relationship between pore structure and thermal conductivity of foamed concrete. Journal of Wuhan University of Technology 3(3): 20-24. https://doi.org/10.3963/j.issn.1671-4431.2013.03.005

[32] Hasselman DHP. (1987). J Comp Mater 21: 508. 